\title{
SEGREGATION RATE AND TRANSPORT MECHANISM OF VOLATILE-BEARING MELT IN THE DEEP MANTLE
}

\author{
Shatskiy*A. ${ }^{1,2}$, Litasov K.D. ${ }^{1,2}$, Ohtani E. ${ }^{1}$ \\ ${ }^{1}$ Dept. of Earth and Planetary Materials Science, Graduate School of Science, Tohoku University, Sendai, Japan \\ ${ }^{2}$ V.S. Sobolev Institute of Geology and Mineralogy SB RAS, Novosibirsk, Russia
}

\section{INTRODUCTION}

There are many direct and indirect evidences of carbonatite and hydrous fluid/melt segregation in the deep mantle during the Earth's history. A particular example is the source regions of kimberlite and lamproite, which can originate from more than $250 \mathrm{~km}$ depth. On the basis of the experimental studies they would correspond to contrast volatile regimes: kimberlite clearly requires abundant $\mathrm{CO}_{2}$ in the source, whereas lamproite requires an $\mathrm{H}_{2} \mathrm{O}$-rich source .

Another example is the forming medium of lithospheric diamonds. The composition of micro-inclusions in "cloudy" and "fibrous" diamonds from different localities indicates that their forming media were represented by ultrapotassic super-critical fluid with different $\mathrm{H}_{2} \mathrm{O} / \mathrm{CO}_{2}$ ratios [1]. Indeed, high-pressure experiments at 6-7.5 $\mathrm{GPa}$ confirm that water-bearing alkali carbonates and $\mathrm{CO}_{2}-\mathrm{H}_{2} \mathrm{O}$ fluid are the most probable media, which are capable to initiate diamond crystallization at the conditions of lithospheric mantle [2].

Since the average concentrations of carbon and hydrogen in primitive mantle would not exceed 100 and 120 wt ppm, respectively [3], the volatile segregation over a broad mantle region should be involved to explain the local abundance of $\mathrm{CO}_{2}$ and/or $\mathrm{H}_{2} \mathrm{O}$. Significant enrichment of such fluids in incompatible trace elements also implies their long infiltration history through the large volumes of mantle rocks. However, mechanisms and forces driving fluid transport and segregation in the deep mantle are poorly understood.

The majority of models considers partially molten matrix, in which buoyancy driven upward percolation of melt occurs through the interconnected interstices [4], wherein the melt flux is resisted by deformation of silicate rock, which occurs by solid-state diffusion [5]. In this model the melt is poor solvent of solid and/or does not wet grain boundaries. That is understood that the melt is poor solvent of solid and/or does not wet grain boundaries. Although this is good approximation for the melt segregation in the shallow mantle (e.g. basalts in the asthenosphere), this approach cannot be directly applied for hydrous fluid and carbonatite melt segregation, because at mantle PT-conditions they are excellent silicate solvents and exhibit enhanced wetting properties . In addition, the porous flow model faces obvious difficulties to explain fluid segregation in the case of the lack of interconnectivity, i.e. in the case of trace amounts of fluid dispersed in the crystalline framework [6].

In contrast, dispersed fluid droplets can infiltrate through the crystalline framework by a dissolutionprecipitation mechanism, wherein migration proceeds due to silicate dissolution ahead and crystallization astern [7]. Among the variety of driving forces promoting fluid migration by the dissolution-precipitation only a capillary force has been studied extensively concerning to the mantle [8]. In fact, this force would counteract the melt segregation. The force driving directional fluid flow such as nonhydrostatic stress $[9,10]$ are required.

In this paper we measured $\mathrm{MgSiO}_{3}$ and $\mathrm{Mg}_{2} \mathrm{SiO}_{4}$ flux through carbonatite melt and hydrous fluid layers in the thermal gradient field under transition zone and lower mantle conditions. Using obtained data we calculated silicate diffusivity in the melt/fluid and estimated possible migration rates of dispersed fluid/melt droplets in the deep mantle by means of dissolution-precipitation driven by nonhydrostatic stress.

\section{EXPERIMENTAL APPROACH}

In the melt infiltration process, the flux follows the general relation: Flux $=($ Permeability $) \times($ Driving force $)$. To accommodate the flux of the equilibrium melt into the nonporous solid aggregate, an equal counterflux of solid must exist. The permeability is determined by either diffusive or convective mass transfer of solute through fluid or by crystal growth kinetics. To study melt migration we used thermal gradient as a driving force (Fig. 1).

The diffusive flux can be expressed using Fick's first law as

$$
f_{D}=D \frac{C_{S}^{\prime}-C_{i}^{\prime}}{l},
$$




\section{$10^{\text {th }}$ International Kimberlite Conference, Bangalore - 2012}

where $D$ is the diffusion coefficient and $l$ is the width of the solution layer, $C_{i}$ ' and $C_{S}$ ' are solute concentration [in $\left.\mathrm{mol} / \mathrm{m}^{3}\right]$ at the high-temperature side (dissolution region) and low-temperature side (growth region). The overall solute counterflux is not determined by bulk transport only, but proceeds by combined dissolution of source, diffusive mass transport, and subsequent crystal growth. Since the dissolution is generally controlled by volume diffusion, it can be omitted from the consideration. Hereinafter the "crystal growth" implies complex process including: (i) diffusion of the solvated molecules through a concentration boundary layer around growing crystal, (ii) diffusion of absorbed solvated molecules along crystal surface toward active growth centers, and (iii) incorporation of the molecules into the crystal lattice. The crystal growth component can be expressed by an empirical equation of power-law form as $\quad f_{G}=k\left(C_{i}-C_{E}\right)^{q}$,

where $k$ is the overall rate constant, $C_{i}$ and $C_{E}$ are the actual and equilibrium solute concentrations [in wt fraction] in the cool part of the sample chamber, and $q$ is the order of the kinetic reaction of crystal growth, which usually varies between 1 and 2 .

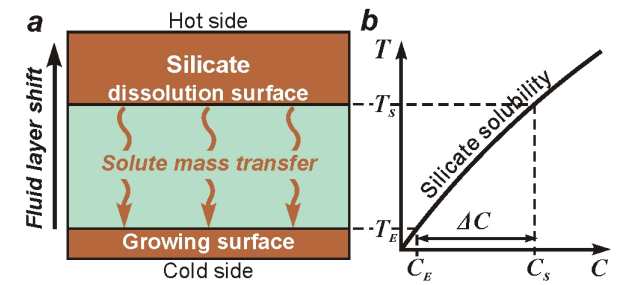

Fig. 1. Melt layer movement through the solid silicate by means dissolution-precipitation driven by silicate solubility difference in thermal gradient field, $\Delta C=C_{S}\left(T_{S}\right)-C_{E}\left(T_{E}\right)$.

Experimentally the overall solute flux can be estimated at steady state conditions from the increase of the amount of solid, $d m$, transported over period of time, $d t$, through the cross-section area of the capsule, $A$ :

$$
f=\frac{d m}{A \cdot d t}
$$

At steady state conditions, the flux of solute molecules through the bulk solution is equal to the crystal growth component, $f_{D}=f_{G}=f$. To extrapolate the rate obtained in the experiments at high supersaturation to that in the mantle, we assume that the migration rate is limited by the diffusion step, $q=1$, rather than by the surface reaction step, $q>1$ in Eq. 2. The validity of this assumption is discussed in the Section 5.2.

\section{EXPERIMENTAL PROCEDURE}

Experiments were conducted using a scaled-up Kawaicell and USSA-5000 ton press [11]. Experimental procedures were the same as described in our previous papers $[12,13]$. The axial thermal gradient across the sample was estimated to be $20 \pm 5{ }^{\circ} \mathrm{C} / \mathrm{mm}$ at $1500{ }^{\circ} \mathrm{C}$. The composition of the starting materials is shown in Table 1 .
The weight of starting materials and recovered silicate crystals and source was measured using balance with the accuracy of $\pm 0.01 \mathrm{mg}$. The weight of recovered silicate crystals and source was also confirmed by estimation of their volumes inferred from linear dimensions measured using SEM images. Silicate solubility was calculated from the initial weight of solvent and silicate source and total weight of recovered silicate crystals. The obtained phases were identified using a microfocused X-ray diffractometer and electron microprobe analyzer.

\section{EXPERIMENTAL RESULTS}

Results are shown in Table 1 and illustrated in Fig. 2.

Table 1. Experimental results on silicate recrystallization through solution layer in thermal gradient filed $\left(\mathrm{TG}=20^{\circ} \mathrm{C} / \mathrm{mm}\right)$

\begin{tabular}{|c|c|c|c|c|c|c|c|c|c|c|c|c|}
\hline \multicolumn{7}{|c|}{ Experimental conditions } & \multicolumn{3}{|c|}{ Recovered } & \multicolumn{3}{|c|}{ Calculated } \\
\hline \multirow{2}{*}{$\stackrel{\Xi}{\Xi}$} & & \multirow{2}{*}{ 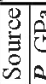 } & \multirow{2}{*}{$\begin{array}{l}\tilde{D} \\
\tilde{D} \\
\Omega^{\prime \prime}\end{array}$} & \multirow{2}{*}{\begin{tabular}{l|}
0 \\
0 \\
5
\end{tabular}} & \multirow{2}{*}{$\begin{array}{c}\boldsymbol{\tau} \\
\min \end{array}$} & \multirow{2}{*}{$\begin{array}{c}C, \\
\text { wt. } \%\end{array}$} & \multirow{2}{*}{$\underset{\mathrm{mm}}{\boldsymbol{d}}$} & \multicolumn{2}{|c|}{$\boldsymbol{M}, \mathrm{mg}$} & \multirow{2}{*}{$\begin{array}{c}\boldsymbol{l}, \\
\mathrm{mm}\end{array}$} & \multirow{2}{*}{$\begin{array}{c}\boldsymbol{C}_{\boldsymbol{e}}, \\
\text { wt. } \%\end{array}$} & \multirow{2}{*}{$\underset{\mathrm{g} / \mathrm{s} / \mathrm{cm}^{2}}{f,}$} \\
\hline & & & & & & & & HT & LT & & & \\
\hline 1 & & & & & 115 & 62 & 1.9 & 11.3 & 0.1 & 0.94 & 22.5 & $4.442 \times 10^{-7}$ \\
\hline 2 & U & (ص) & & & 155 & 55 & 1.9 & 10.8 & 0.4 & 1.21 & 23.3 & $10^{6}$ \\
\hline 3 & $\sum$ & 蒈 & 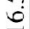 & 5 & 240 & 59 & 1.9 & 10.8 & 1.8 & 1.32 & 24.5 & $9.405 \times 10^{-6}$ \\
\hline 4 & $\approx$ & $\overline{0}$ & & & 450 & 64 & 1.9 & 4.9 & 6.7 & 0.92 & 28.3 & $1.390 \times 10^{-5}$ \\
\hline 5 & & & & & 480 & 64 & 1.9 & 3.9 & 7.4 & 0.95 & 30.0 & $1.360 \times 10^{-5}$ \\
\hline 6 & & & & & 50 & 70.1 & 1.9 & 12.2 & 0.2 & 0.93 & 30.5 & $2.536 \times 10^{-6}$ \\
\hline 7 & 志 & & & & 120 & 73.6 & 1.9 & 12.8 & 2.5 & 0.79 & 34.2 & $1.889 \times 10^{-5}$ \\
\hline 8 & $\sum$ & (1) & & 8 & 180 & 68.9 & 2.0 & 8.4 & 5.0 & 1.06 & 31.1 & $2.237 \times 10^{-5}$ \\
\hline 9 & & & 寸 & in & 260 & 68.9 & 1.9 & 5.2 & 8.2 & 0.95 & 31.0 & $2.319 \times 10^{-5}$ \\
\hline 10 & & $\vec{a}$ & i & & 20 & 87.4 & 1.8 & 2.1 & 9.6 & 1.30 & 73.2 & $\geq 3.080 \times 10^{-4}$ \\
\hline 11 & 0 & 다 & & & 60 & 90.4 & 1.8 & 0 & 11.0 & 1.27 & 78.3 & $>1.175 \times 10^{-4}$ \\
\hline 12 & 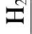 & & & & 16 & 82.2 & 1.8 & 5.3 & 5.3 & 1.00 & 47.2 & $\geq 2.139 \times 10^{-4}$ \\
\hline 13 & & & & & 45 & 83.9 & 1.75 & 0 & 11.9 & 0.80 & 49.0 & $>1.556 \times 10^{-4}$ \\
\hline
\end{tabular}

$\boldsymbol{\tau}$ - run duration; $\boldsymbol{C}$-silicate concentration in system; $\boldsymbol{d}$ - sample diameter; $\boldsymbol{M}$ - weight of silicate remaining at HT side and that recrystallized in LT side; $\boldsymbol{l}$ - thickness of solvent layer; $\boldsymbol{C}_{\boldsymbol{e}}$ - silicate solubility in solvent; $\boldsymbol{f}$ solute flux; $\mathrm{KMC}-\mathrm{K}_{2} \mathrm{Mg}\left(\mathrm{CO}_{3}\right)_{2} ; \mathrm{KMCH}-\mathrm{K}_{2} \mathrm{Mg}\left(\mathrm{CO}_{3}\right)_{2} \times 2 \mathrm{H}_{2} \mathrm{O}$.

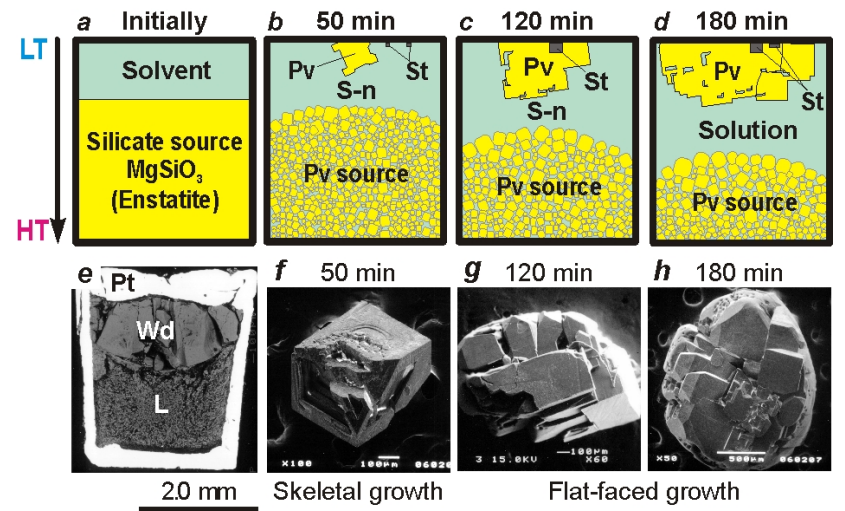

Fig. 2. Illustration of $\mathrm{MgSiO}_{3}$ perovskite recrystallization though the solution layer at $24 \mathrm{GPa}, 1500^{\circ} \mathrm{C}$ and $\mathrm{TG}=20^{\circ} \mathrm{C} / \mathrm{mm}$ in $\mathrm{K}_{2} \mathrm{Mg}\left(\mathrm{CO}_{3}\right)_{2} \times 2 \mathrm{H}_{2} \mathrm{O}$ solvent. (a) Initial sample design. (b-d) Crystallization schemes. (e) Pots experimental sample cross-section. (f-h) Perovskite crystals.

\section{DISCUSSION}

\subsection{Steady and unsteady state mass transfer}

Steady state can be established when the area of growing crystals and dissolving source are larger or equal to the area of the capsule cross-section. In terms of this 


\section{$10^{\text {th }}$ International Kimberlite Conference, Bangalore - 2012}

criterion following time intervals can be defined for the steady state mass transfer: $240-480 \mathrm{~min}$ for $\mathrm{Mg}_{2} \mathrm{SiO}_{4}$ in $\mathrm{KMC}$ at $16.5 \mathrm{GPa}$ and $1700^{\circ} \mathrm{C}, 180-260$ min for $\mathrm{MgSiO}_{3}$ in $\mathrm{KMCH}$ at $24 \mathrm{GPa}$ and $1500^{\circ} \mathrm{C}$, and $\leq 20$ min for $\mathrm{MgSiO}_{3}$ in $\mathrm{H}_{2} \mathrm{O}$ at $24 \mathrm{GPa}$ and $1500^{\circ} \mathrm{C}$. The maximum possible unsteady state period for the last system can be estimated from the time needed to expand the growing crystal surface to the cross-section area of the capsule. Assuming negligibly short induction period preceding nucleation and time independent perovskite growth rate, the unsteady state period does not exceed 5 min. However, the actual value should be somewhat less since an average growth rate during unsteady state exceeds a growth rate estimated from single run, where mass transfer proceeded at unsteady and than at steady state (Fig. 3).
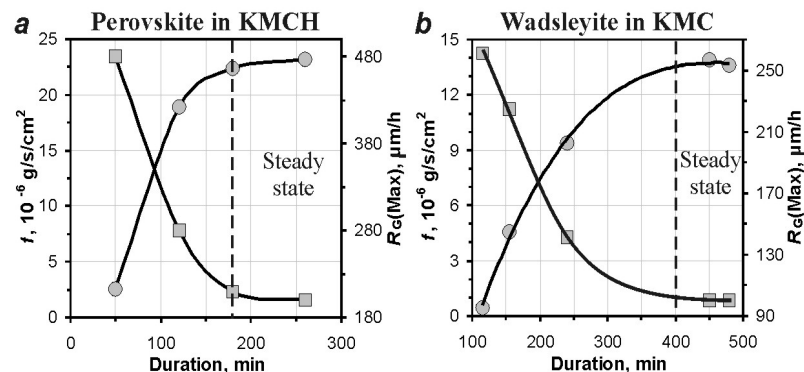

Fig. 3. Changes of silicate flux, $f$ (circles), and maximum crystal growth rate, $R_{G}(\operatorname{Max})$ (squares), with time. Silicate recrystallization was carried out through the solution. (a) $\mathrm{MgSiO}_{3}$ perovskite growth in $\mathrm{K}_{2} \mathrm{Mg}\left(\mathrm{CO}_{3}\right)_{2} \times 2 \mathrm{H}_{2} \mathrm{O}$ solvent at $24 \mathrm{GPa}$ and $1500^{\circ} \mathrm{C}$. (b) $\mathrm{Mg}_{2} \mathrm{SiO}_{4}$ wadsleyite growth in $\mathrm{K}_{2} \mathrm{Mg}\left(\mathrm{CO}_{3}\right)_{2}$ solvent at $16.5 \mathrm{GPa}$ and $1700^{\circ} \mathrm{C}$.

The surface area coverage is a necessary but insufficient criterion. Therefore, time dependence of silicate flux, $f$, and growth rate, $R_{G}(\operatorname{Max})$, was studied in the experiments with various duration. As illustrated in Fig. 3, $f$ increases and $R_{G}(\operatorname{Max})$ decreases rapidly with time achieving nearly constant values at certain run duration, namely $\sim 200 \mathrm{~min}$ in $\mathrm{KMCH}$ and $\sim 400 \mathrm{~min}$ in KMC. The cause of the observed dynamics can be illustrated as follows. In the beginning of a run at time after achieving critical concentration in the cool region, i.e. $C_{i}>C_{3 D}$, the nucleation occurs (Fig. 4a). Even negligible amount of material consumed on the formation of
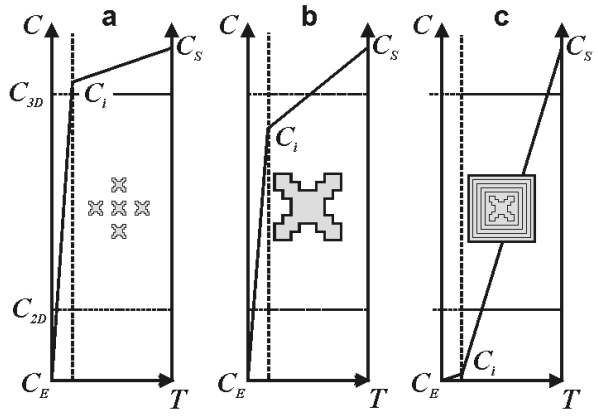

Fig. 4. Expected evolution of solute concentration profiles along the solution layer sandwiched by the hot dissolving and cool growing silicate layers at unsteady $(\mathrm{a}, \mathrm{b})$, and steady (c) state conditions. (a) Spontaneous nucleation. (b) Skeletal growth. (c) Flat faceted growth. $C_{S}$ - the solute concentration near silicate source or equilibrium silicate solubility in the hot region; $C_{i}$ - the actual solute concentration in the cool region; $C_{E}-$ the equilibrium silicate solubility in the cool region; $C_{3 D}$ - the supersaturation required for spontaneous nucleation; $C_{2 D}$ - the supersaturation separating the region of skeletal growth and flat-faceted growth.

1 to 5 crystallites is sufficient to decrease $C_{i}$ below $C_{3 D}$, which terminates further nucleation (Fig. 4b). While the crystals are small, the diffusion distance of solvated molecules to crystal facets from the supersaturated melt is small. Accordingly, the growth rate is maximal. The small diffusion pass of solvated molecules causes inhomogeneous concentration of solute around the crystal (higher at corners and edges and lower near facets). As a result skeletal growth occurs. As the silicate components diffuse from the bulk melt (not from the source), their diffusion length increases until it become equal to the distance from the source to the crystals. After this point the steady state mass transfer is established.

\subsection{Mass transfer limiting step}

Either crystal growth or volume diffusion becomes the slowest step, which predominantly determines the overall solute flux. In our experiments the bulk supersaturation exceeds that required for spontaneous nucleation, i.e. $C_{S}>C_{3 D}$ (Fig. 4). Otherwise, crystallization would not occur because we did not use seed crystals. At steady state, we observed the flat-facet growth (Fig. 2g,h). This morphology corresponds to the low supersaturation near crystal/solution interface, i.e. $C_{E}<C_{i}<<C_{2 D}$ (Fig. 4c). Hence, the solute concentration in the cool region is significantly lower than that, which can be potentially established, $C_{i}>C_{S}$ (Fig. 4c). It means that crystals grow fast enough to consume all solute delivered from the source. Although negligibly low driving force of growth, $C_{i}-C_{S}<<C_{2 D}-C_{E}$, it easily compensates diffusion mass transfer, which is driven by much larger concentration difference, $C_{S}-C_{i} \approx C_{3 D}-C_{E}$ (Fig. 4c). This suggests low $D / k$ ratio (Eq. 1, 2). Consequently, the volume diffusion mass transfer predominantly resists the overall solute flux at steady state in our experiments.

\subsection{Silicate diffusivity}

In the case of the thermal gradient driving force, the diffusive flux can be expressed through the slope of silicate solubility curve and thermal gradient,

$$
f_{D}=D \times\left(\frac{d C^{\prime}}{d T}\right) \times\left(\frac{d T}{d l}\right) .
$$

Thus, combination of Eq. 4 and silicate flux estimated experimentally at steady state using Eq. 3, enables extraction of diffusivity. Silicate solubility was estimated from the mass of initial silicate source and solvent and the mass of recovered source and grown crystals, $C_{e}=M_{\text {silicate }}^{\text {disslved }} /\left(M_{\text {silicate }}^{\text {dissolved }}+M_{\text {solvent }}^{\text {inital }}\right), \quad$ where $M_{\text {silicate }}^{\text {dissolved }}=M_{\text {source }}^{\text {initial }}-\left(M_{\text {source }}^{\text {recov. }}+M_{\text {crystals }}^{\text {grown }}\right)$. We neglect the slight deviation of solute composition in hydrous melt and $\mathrm{KMCH}$ from $\mathrm{MgSiO}_{3}$ stoichiometry $(\mathrm{Mg} / \mathrm{Si} \sim 1.15$ [12]) assuming congruent dissolution. The slopes of silicate solubility curves were estimated from our unpublished experimental 


\section{$10^{\text {th }}$ International Kimberlite Conference, Bangalore - 2012}

data and estimated melting points of water $\left(600^{\circ} \mathrm{C}\right.$ at 24 $\mathrm{GPa}$ [14]), $\mathrm{MgSiO}_{3}\left(2280^{\circ} \mathrm{C}\right.$ at $24 \mathrm{GPa}$ [15]), and $\mathrm{Mg}_{2} \mathrm{SiO}_{4}$ $\left(2200^{\circ} \mathrm{C}\right.$ at $16.5 \mathrm{GPa}$ [15]). To calculate molar concentration, density of solution, $\rho_{\text {solution }}$, at given pressure and temperature, $C^{\prime}=\frac{C_{\text {solute }} / M_{\text {solute }}}{100 / \rho_{\text {solution }}}$,

has to be known. Density of hydrous melt was estimated from known silicate solubility and HPHT density data of hydrous and dry $\mathrm{MgSiO}_{3}$ melt [16] assuming linear temperature- and water concentration-density dependences. Densities of hydrous and dry carbonatite melts were calculated from the density of $\mathrm{MgSiO}_{3} \pm \mathrm{H}_{2} \mathrm{O}$ melt [16] and the partial molar volume of $\mathrm{CO}_{2}$ [17]. The latter was corrected to the partial molar volume of $\mathrm{CO}_{2}$ at 1500 and $1700^{\circ} \mathrm{C}$ using the thermal expansion data at ambient pressure [18]. The density estimates are summarized in Table 2. The accuracy of estimating silicate weight $( \pm 0.01$ $\mathrm{mg})$, recovered capsule diameter $( \pm 15 \%)$, solubility slope $( \pm 40 \%)$, and thermal gradient $( \pm 50 \%)$ would lead to a \pm 60 $\%$ error in $D$.

Table 2. Estimates of silicate solubility and diffusive transport in carbonate melt and hydrous fluid at mantle $P T$ conditions

\begin{tabular}{lccccccc}
\hline Solvent & \multicolumn{2}{c}{$\mathrm{KMC}^{2}$} & \multicolumn{2}{c}{$\mathrm{KMCH}$} & \multicolumn{4}{c}{$\mathrm{H}_{2} \mathrm{O}$} \\
Silicate & \multicolumn{2}{c}{$\mathrm{Mg}_{2} \mathrm{SiO}_{4}$} & \multicolumn{2}{c}{$\mathrm{MgSiO}_{3}$} & \multicolumn{3}{c}{$\mathrm{MgSiO}_{3}$} \\
$\boldsymbol{P}, \mathrm{GPa}$ & 16.5 & \multicolumn{2}{c}{24} & & 24 & \\
$\boldsymbol{T},{ }^{\circ} \mathrm{C}$ & 1600 & 1700 & 1500 & $1700 ”$ & 1350 & 1500 & $1700 "$ \\
$\boldsymbol{C}_{\boldsymbol{e}}, \mathrm{wt} \%$ & 16.8 & 25.7 & 31.7 & 47.4 & 48.1 & 75.7 & 88.8 \\
$\boldsymbol{\rho}_{\text {solution }}, \mathrm{g} / \mathrm{cm}^{3}$ & 3.00 & 3.02 & 3.23 & 3.29 & 1.99 & 2.94 & 3.39 \\
$\boldsymbol{C}_{\boldsymbol{e}}, \times 10^{3} \mathrm{~mol} / \mathrm{m}^{3}$ & 3.59 & 5.52 & 10.2 & 15.5 & & 22.2 & 30.0 \\
$\boldsymbol{d} \boldsymbol{C} / \boldsymbol{d} \boldsymbol{T}, \mathrm{wt} \% /{ }^{\circ} \mathrm{C}$ & 0.09 & 0.10 & 0.09 & 0.11 & 0.28 & 0.11 & 0.05 \\
$\boldsymbol{f}, \times 10^{-3} \mathrm{~mol} / \mathrm{m}^{2} / \mathrm{s}$ & - & 1.0 & 2.3 & - & 21 & 31 & - \\
$\boldsymbol{D}, \times 10^{-9} \mathrm{~m}^{2} / \mathrm{s}$ & 2.0 & 2.4 & 3.9 & 5.6 & $\geq 19$ & $\geq 50$ & $\geq 71$ \\
\hline
\end{tabular}

* - Diffusivity was estimated assuming the same activation energy as reported for $\mathrm{CO}_{3}{ }^{2-}$ in carbonate melt, $48 \mathrm{~kJ} / \mathrm{mol}$ (see capture Fig. 11 for the references). $* *$ - Diffusivity was estimated assuming the same activation energy as reported by [19] for $\mathrm{SiO}_{2}$ diffusion in $\mathrm{H}_{2} \mathrm{O}$ at $1 \mathrm{GPa}, 52 \mathrm{~kJ} / \mathrm{mol}$. $\mathrm{KMC}-\mathrm{K}_{2} \mathrm{Mg}\left(\mathrm{CO}_{3}\right)_{2} ; \mathrm{KMCH}-\mathrm{K}_{2} \mathrm{Mg}\left(\mathrm{CO}_{3}\right)_{2} \times 2 \mathrm{H}_{2} \mathrm{O}$.

The obtained diffusivities are listed in Table 2 and presented in Fig. 5, which also includes the lower pressure data for $\mathrm{SiO}_{2}$ diffusivity in silicate melt and hydrous fluid and $\mathrm{CO}_{3}{ }^{2-}$ diffusivities in carbonate melt. Note that in contrast to the solid and polymerized liquid, the diffusion coefficients of different elements in the depolymerized melt/fluid are very similar, i.e. coincide within one order of magnitude. In accordance with our results the silicate diffusivity varies in the following sequence: $\mathrm{H}_{2} \mathrm{O}>$ $\mathrm{K}_{2} \mathrm{Mg}\left(\mathrm{CO}_{3}\right)_{2} \times 2 \mathrm{H}_{2} \mathrm{O}>\mathrm{K}_{2} \mathrm{Mg}\left(\mathrm{CO}_{3}\right)_{2}$ (Fig. 5). Extrapolation of $\mathrm{SiO}_{2}$ diffusivity in a hydrous supercritical fluid measured at pressure of $1 \mathrm{GPa}$ and temperatures up to $1500^{\circ} \mathrm{C}$ [19] gives one order of magnitude higher diffusivity than that of $\mathrm{MgSiO}_{3}$ in hydrous melt at $1500^{\circ} \mathrm{C}$ and $24 \mathrm{GPa}$ (Fig. 5). It can be attributed to the higher silica concentration in hydrous melt/fluid in our study $(\sim 26 \mathrm{~mol} . \%)$ than that in [19] ( $\leq 4$ mol.\%). Silica polymerization in the fluid depends strongly on the bulk $\mathrm{SiO}_{2}$ concentration. At the concentration level below $20 \quad$ mol.\% $\quad \mathrm{SiO}_{2}, \quad \mathrm{H}_{4} \mathrm{SiO}_{4}$ monomers and $\mathrm{H}_{6} \mathrm{Si}_{2} \mathrm{O}_{7}$ dimers are the major silica species, whereas at the concentrations above $20 \mathrm{~mol} . \% \mathrm{SiO}_{2}$ they are replaced by higher oligomers [20].

The diffusivity of $\mathrm{CO}_{3}{ }^{2-}$ in carbonate melt at $1 \mathrm{~atm}$ also exceeds that of $\mathrm{Mg}_{2} \mathrm{SiO}_{4}$ in $\mathrm{KMC}$ melt at $16.5 \mathrm{GPa}$ by an order of magnitude (Fig. 5). This difference can be explained as follows. The carbonate melt has flexible atomic structure, which diminishes diffusivity difference between contrast diffusant . However, addition of more than 33 mol.\% silica into carbonate melt leads to the polymerization of silicon tetrahedra [21]. Therefore, the diffusivity difference between our and previous data would be attributed to the identity of the diffusant and more rigid atomic structure of carbonatite melt containing $38 \mathrm{~mol} \%$ $\mathrm{SiO}_{2}$. The pressure effect on the carbonatite melt structure, which can be expected by the analogy with phase transitions in solid carbonates can be considered as an another reason for observed diffusivity difference [22].

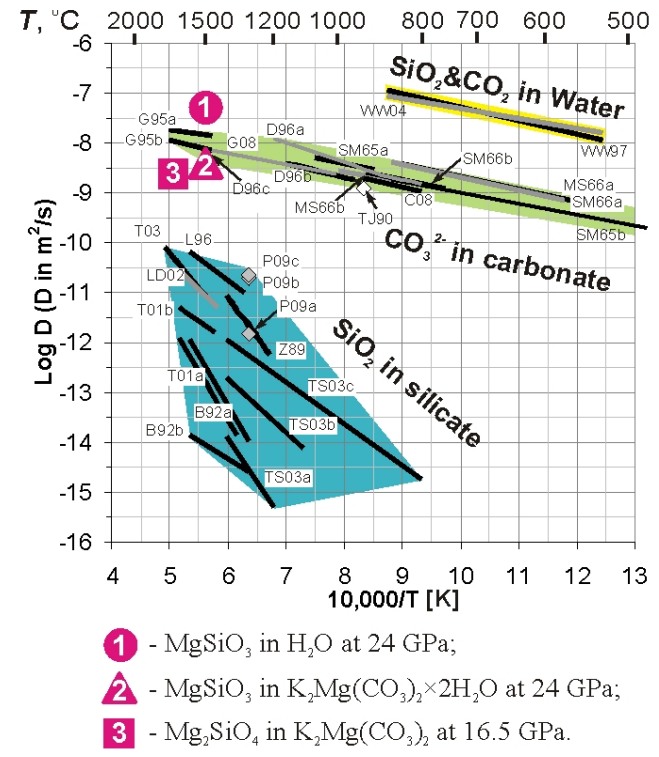

Fig. 5. Arrhenius diagram showing silicate diffusivity in hydrous (1), hydrous carbonatite (2), and carbonatite melts (3) obtained in this study at transition zone and lower mantle pressures. Literature data on the diffusion characteristics of hydrous supercritical fluid and hydrous silicate, "dry" silicate, and carbonatite melts obtained at shallow mantle and ambient pressures are shown for the comparison.

\subsection{Melt segregation in the deep mantle}

Although silicate diffusivities in hydrous and carbonatite melt are high, the silicate flux and therefore migration rate in the real Earth's mantle conditions are essentially determined by the driving force, i.e. concentration difference (Eq. 1). The latter can be caused by nonhydrostatic stress in convective mantle, which is estimated in the range of $0.1-10 \mathrm{MPa}$. In this section we estimate the melt migration rates driven by these forces.

Dissolution/precipitation of solids is fully described by the surface chemical potential, $\mu$. If a nonhydrostatic stress, $\sigma$, affects the solid particle in addition to the hydrostatic pressure, the chemical potential in the solid is increased by 


\section{$10^{\text {th }}$ International Kimberlite Conference, Bangalore - 2012}

$$
\Delta \mu=V_{m} \sigma,
$$

where $V m$ is the molar volume of solid [9]. Mineral solubility at stressed state is given by

$$
C^{\prime}=C_{e}{ }^{\prime} \exp (\Delta \mu / R T)=C_{e}{ }^{\prime} \exp \left(V_{m} \sigma / R T\right),
$$

Where $C_{e}$ ' is the mineral solubility (solute molar concentration) at zero stress and $R$ is the gas constant $[9,23]$. This expression has been derived previously by [24]. Thermodynamic considerations [25] show that this approximation is valid not only for the solubility of a mineral in the bulk fluid but also in thin intergranular films existing due to the disjoining pressure. Combining Eqs. 1 and 7 the stress-driven diffusive flux can be expressed as:

$$
f_{D}=\frac{D C_{e}{ }^{\prime}}{l}\left(\exp \left(\frac{\sigma V_{m}}{R T}\right)-1\right) \text {. }
$$

Due to this distribution of concentration in the liquid phase, the crystal is dissolved in a strained zone and the dissolved material diffuses through the liquid and crystallizes at a sink outside the strained contact. This kind of process has been demonstrated by the movement of brine in a $\mathrm{KCl}$ crystal in a stress gradient [10].

The thickness of melt droplet, $l$, was chosen in the range from 0.001 to $0.1 \mathrm{~mm}$ according to the size of syngenetic fluid/melt inclusions in mantle xenoliths. The rates of melt migration estimated form the flux driven by stress are presented in Fig. 6.

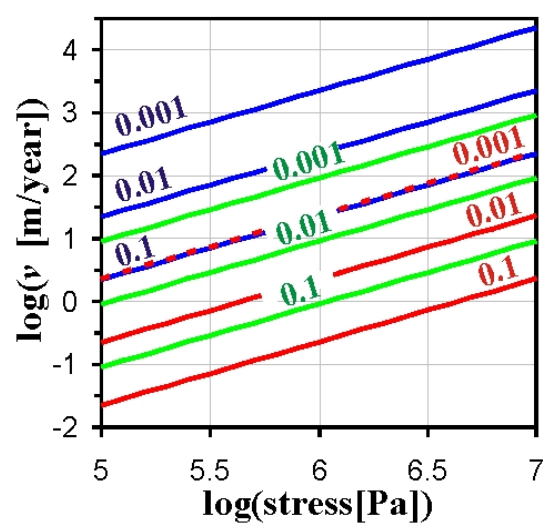

$\mathrm{KMC}$ in $\mathrm{Mg}_{2} \mathrm{SiO}_{4}, 16.5 \mathrm{GPa}, 1600^{\circ} \mathrm{C}$ $\mathrm{KMCH}$ in $\mathrm{MgSiO}_{3}, 24 \mathrm{GPa}, 1700^{\circ} \mathrm{C}$

$\mathrm{HM}$ in $\mathrm{MgSiO}_{3}, 24 \mathrm{GPa}, 1700^{\circ} \mathrm{C}$

Fig. 6. Stress dependent rate of fluid moving through non-porous solid silicate mantle by means of stress-driven dissolution-precipitation mechanism. Numbers are diffusion path length (i.e. fluid inclusion size or thinness of fluid film). Fluid compositions (silicate solubility) are given in Table 2. HM denotes hydrous melt.

As can be seen both melt droplet size and stress have substantial effect on the migration rate. At typical mantle stress of $1 \mathrm{MPa}$ and droplet size or fluid film thickness of $10 \mu \mathrm{m}$ the migration rate of hydrous and $\mathrm{KMCH}$ melts is estimated to be 225 and $9 \mathrm{~m} /$ year, respectively, at $24 \mathrm{GPa}$ and $1700^{\circ} \mathrm{C}$. In the case of $\mathrm{KMC}$ melt at $16.5 \mathrm{GPa}$ and $1600^{\circ} \mathrm{C}$ the migration rate is near $2 \mathrm{~m} /$ year. For comparison the rates of mantle upwelling (ascent plume) would not exceed several centimeters per year, which is 2-4 orders of magnitude slower than the proposed melt migration rates.

To conclude, the melt formation and rock deformation coexist in time and space on a large scale. It is proposed that melting in Earth's mantle occurs primarily in plumes, which are regions of intense deformation [4]. Our data suggest that the dispersed hydrous or carbonatite melt/fluid could rapidly segregate within oxidized domains of the upwelling mantle by means of stress-driven dissolutionprecipitation mechanism. This mechanism may explain early stage of segregation of mantle magmas with source regions deeper than $150-250 \mathrm{~km}$. Furthermore, if the melt/fluid and the silicate matrix were not at chemical equilibrium in respect to trace elements, as would be the case in the mantle, dissolution and precipitation reactions would result in a very efficient exchange of these components between the melt and the matrix.

\section{REFERENSES}

1 Schrauder, M. et al. Geochimica Et Cosmochimica Acta 58, 761-771 (1994).

2 Pal'yanov, Y. N. et al. Nature 400, 417-418 (1999).

3 McDonough, W. F. in Treatise on Geochemistry Vol. 2 (eds H. D. Holland et al.) 547-568 (Oxford: Elsevier - Pergamon., 2003).

4 Kohlstedt, D. L. et al. Annual Review of Earth and Planetary Sciences 37, 561-593, doi:10.1146/annurev.earth.031208.100104 (2009).

5 Cooper, R. F. et al. Tectonophysics 107, 207-233 (1984).

6 McKenzie, D. Earth and Planetary Science Letters 74, 81-91 (1985).

7 Whitman, W. G. American Journal of Science 11, 126-132 (1926).

8 Hammouda, T. et al. Geology 28, 283-285 (2000).

9 Kruzhanov, V. et al. Pure and Applied Geophysics 152, 667-683 (1998).

10 Geguzin, Y. E. et al. Kristallografiya 24, 866-867 (1979).

11 Shatskiy, A. et al. Physics of the Earth and Planetary Interiors, doi:10.1016/j.pepi.2011.1008.1001, doi:10.1016/j.pepi.2011.08.001 (2011).

12 Shatskiy, A. et al. American Mineralogist 92, 1744-1749, doi:10.2138/am.2007.2415 (2007).

13 Shatskiy, A. et al. American Mineralogist 94, 1130-1136, doi:10.2138/am.2009.3150 (2009).

14 Katayama, Y. et al. Physical Review B 81, doi:014109

10.1103/PhysRevB.81.014109 (2010).

15 Liebske, C. Mantle-Melting at High Pressure-Experimental Constraints on Magma Ocean Differentiation Doktors der Naturwissenschaften thesis, Universität Bayreuth, (2005).

16 Mookherjee, M. et al. Nature 452, 983-986 (2008).

17 Ghosh, S. et al. Geophysical Research Letters 34, L22312, doi:10.1029/2007GL031349 (2007).

18 Liu, Q. et al. Mineralogy and Petrology 146, 370-381 (2003).

19 Watson, E. B. et al. Contributions to Mineralogy and Petrology 130, 66-80 (1997).

20 Newton, R. C. et al. Earth and Planetary Science Letters 274, 241 249 (2008).

21 Treiman, A. H. et al. Journal of Geology 91, 437-447 (1983).

22 Cancarevic, Z. P. et al. Chemistry-a European Journal 13, 73307348, doi:10.1002/chem.200601637 (2007).

23 Chernov, A. A. Progress in Crystal Growth and Characterization of Materials 26, 121-151 (1993).

24 Elliott, D. Geological Society of America Bulletin 84, 2645-2664, doi:10.1130/0016-7606(1973)84<2645:dflimr>2.0.co;2 (1973).

25 Heidug, W. K. Journal of Geophysical Research-Solid Earth 100, 5931-5940, doi:10.1029/94jb03100 (1995). 